\title{
Manajemen Intervensi HOT FLUSH dengan Menggunakan BodyWipe
}

Bina Aquari
Akbid Budi Mulia Palembang

Informasi Artikel :

Diterima : 09 April 2021

Direvisi : 15 April 2021

Disetujui : 29 Mei 2021

Diterbitkan : 15 Juni 2021

"Korespondensi Penulis : Binaplb22012@gmail.com

\section{A B S T R A K}

Gejala paling umum yang dialami wanita menopause, yaitu hot flush. Hot Flush adalah perasaan panas yang muncul mulai dari bagian atas tubuh dan menyebar ke wajah. Intervensi yang dilakukan untuk mendinginkan hot flush dengan menggunakan body wipe. Body Wipe adalah alat penyeka tubuh yang memberikan kesegaran. Penelitian ini bertujuan untuk mengetahui pengaruh body wipe sebagai manajemen intervensi hot flush pada wanita menopause di Klinik/BP Anisa. Penelitian ini merupakan eksperimen dengan menggunakan rancangan eksperimen semu. Data diperoleh dengan kuisioner untuk karakteristik umur, pendidikan dan pekerjaan sedangkan observasi untuk suhu sebelum dan sesudah diberi manajemen intervensi body wipe. Sampel penelitian ini adalah wanita menopause berjumlah 12 orang yang berkunjung untuk berobat di Klinik/BP Anisa. Metode analisis data menggunakan uji statistik wilcoxon. Analisis Univariat menunjukan suhu tinggi pada suhu sebelum diberi manajemen intervensi body wipe (100\%), sesudah diberi manajemen intervensi body wipe suhu normal (91.7\%) dan suhu tinggi (8.3\%), umur fase menopause $(100 \%)$, pendidikan bawah $(100 \%)$, pekerjaan secara mandiri (100\%). Untuk analisis bivariat terdapat 12 wanita menopause (100\%) dengan hasil suhu inti tubuh lebih rendah setelah diberi manajemen intervensi body wipe dibandingkan sebelum diberi manajemen intervensi body wipe. Hasil penelitian ini menunjukan bahwa manajemen intervensi dengan menggunakan body wipe dapat berpengaruh dalam mengatasi hot flush pada ibu menopause di Klinik/BP Anisa dengan nilai nilai $\mathrm{p}=0,001$. Body wipe dapat digunakan sebagai manajemen intervensi untuk mengatasi hot flush.

\section{Kata Kunci : HOT FLUSH}

\begin{abstract}
The most common symptoms experienced by menopausal women, the hot flush. Hot Flush is feeling the heat that comes from the upper part of the body and spreads to the face. Interventions to cool the hot flush by using a body wipe. Wipe body is a body polishing tool that can provide freshness.This study aimed to determine the effect of body wipe as management intervention in women menopausal hot flush in Clinic/BP Anisa This is an experimental study using a quasi-experimental design. Data obtained by questionnaire to the characteristics of age, education and employment, while observations for given temperature before and after the intervention management body wipe. The study sampel was postmenopausal women are 12 people in the Clinic/BP Anisa. Methods of statistical data analysis using Wilcoxon test. Univariate analysis showed a high temperature before the temperature given intervention management body wipe (100\%), after a given intervention management body wipe normal temperature (91.7\%) and high temperature (8.3\%), age of menopause phase (100\%), lower education (100\%), work independently (100\%). For the bivariate analysis, there were 12
\end{abstract}


postmenopausal women (100\%) with the lower core body temperature after being given a body wipe management intervention than before the intervention given the management body wipe. These results indicate that management interventions using a body can wipe influential in addressing maternal menopausal hot flush in Clinic/BP Anisa with a value of $p=0.001$. Body wipe can use as management intervention to address the hot flush.

\section{Key words: HOT FLUSH}

\section{PENDAHULUAN}

Menopause merupakan peristiwa yang alamiah dan normal terjadi pada seorang wanita dengan penghentian permanen menstruasi (haid), berarti pula akhir dari masa reproduksi. Perubahan hormon endrokin yang terlibat selama bertahun tahun dalam kehidupan wanita, terutama disebabkan oleh kehilangan fungsi ovarium yang semakin meningkat. Tubuh wanita memiliki persediaan sel telur yang terbatas dan menopause terjadi ketika indung telur mulai kehabisan sel telur dan menyebabkan berhentinya produksi hormon seks wanita estrogen dan progesterone. Menopause terjadi pada akhir siklus menstruasi yang terakhir tetapi kepastiannya baru diperoleh jika seorang wanita sudah tidak mengalami siklus haidnya selama minimal 12 bulan. (Proverawati, A \& Sulityawati, E. 2010)

Depkes RI memperkirakan penduduk Indonesia pada tahun 2020 akan mencapai 262,6 juta jiwa dengan jumlah wanita hidup dalam usia menopause sekitar 30,0 jiwa dengan usia rata - rata menopause 49 tahun. Sedangkan data yang didapat dari Klinik/BP Anisa terdapat 39 wanita menopause.

Gejala paling umum yang dialami wanita menopause, yaitu hot flush. Hot Flush adalah perasaan panas yang muncul mulai dari bagian atas tubuh dan menyebar ke wajah, bahkan kadang - kadang sampai ke seluruh tubuh. Hot flush terjadi ketika tiba tiba ada pembesaran (pelebaran) pembuluh darah dalam kulit yang menyebabkan panas dilepaskan. Flushing berkaitan dengan turunnya estrogen yang menyebabkan ketidakseimbangan hormon dalam hipotalamus.
Pada beberapa wanita, keluhan hot flush disertai oleh gejala palpitasi, rasa berdenyut pada kepala dan leher, nyeri kepala, kadang mual, dan ansietas. Perubahan fisiologis yang dapat terlihat adalah peningkatan temperature tubuh, denyut nadi dan nafas. Hot flush juga bisa diprovokasi oleh minuman panas, alkohol, stress, emosional dan kegiatan fisik yang berlebihan. Meskipun demikian, dapat timbul setiap saat tanpa didahului suatu keadaan tertentu dan dapat juga menimbulkan gangguan tidur. Dampak dari hot flush menimbulkan rasa emosi, gerah, kecemasan, dan ketidaknyamanan.

Untuk mengatasi masalah hot flush adalah dengan cara mendinginkan efek hot flush, menggunakan alat penyeka tubuh (body wipe). Body wipe menjadi manajemen intervensi untuk mengatasi masalah hot flush. Body wipe adalah alat penyeka tubuh yang berguna untuk membersihkan kotoran dari tubuh dan memberikan kesegaran. Manfaat dari body wipe adalah memberikan kesegaran pada kulit dan membersihkan kulit dari kotoran. Keuntungan yang didapat adalah lebih praktis dan mudah dalam mengurangi sensasi panas pada kulit, terdapat di warung atau mini market terdekat, serta harganya yang ekonomis. Menggunakan body wipe yang bersifat non alkohol dan juga telah teruji secara dermatologis mengandung formula yang ringan, lembut dan aman dipakai (tanpa pedih di mata).

Cara melakukan intervensi dengan menggunakan body wipe: buka bungkus tisu basah (body wipe) dan ambil tisu basah (body wipe) selembar, lalu ditutup kembali bungkusnya. Kemudian tempelkan pada pada bagian kulit yang terasa panas, mulai dari bagian wajah ke leher hingga ke dua lengan 
tangan selama 3 - 5 menit. Setelah 5 menit, angkat body wipe dari permukaan kulit.

Berdasarkan penjelasan di atas, ternyata body wipe dapat digunakan untuk mengatasi hot flush. Jika dilihat dari manfaat dan fungsinya sebagai salah satu intervensi untuk mengatasi hot flush, maka penulis tertarik untuk mengetahui pengaruh body wipe sebagai manajemen intervensi hot flush pada wanita menopause.

\section{METODE PENELITIAN}

Jenis penelitian yang dilakukan adalah jenis penelitian kuantitatif dengan menggunakan rancangan eksperimen semu (quasi experiment design), dimana pengumpulan data dengan cara pengamatan dan wawancara. Penelitian dilakukan di Klinik/BP Anisa yang dilakukan pada tanggal 25 Maret sampai dengan 29 April 2021.

Populasi yang digunakan dalam penelitian ini adalah ibu - ibu menopause yang berjumlah 39 orang yang berkunjung di Klinik/BP Anisa . Pengambilan sampel dalam penelitian ini dilakukan dengan menggunakan teknik Purposive Sampling. Jumlah responden pada penelitian ini hanya 12 wanita menopause, karena proses penelitian memiliki keterbatasan waktu penelitian.

Kriteria inklusi dalam penelitian ini adalah wanita menopause yang mengalami hot flush, secara sukarela ikut sebagai sampel penelitian, mengikuti proses penelitian sampai selesai, wanita menopause tanpa penyakit komplikasi yang berbahaya untuk intervensi pada penelitian ini. Kriteria eksklusi pada penelitian ini adalah wanita menopause yang tidak sedang menggunakan kipas angin saat dilakukan intervensi, wanita menopause yang tidak mengalami hot flush, tidak ikut sebagai sampel penelitian, tidak mengikuti proses penelitian sampai selesai, wanita menopause berpenyakit komplikasi yang berbahaya untuk intervensi pada penelitian ini.

Instrumen yang digunakan dalam penelitian ini adalah lembar observasi sederhana yang terdiri dari karakteristik umur, pendidikan dan pekerjaan wanita menopause, suhu inti tubuh sebelum dan sesudah diberi manajemen intervensi body wipe.

Sebelum dilaksanakan penelitian ini, peneliti telah mendapat persetujuan dari dokter penanggung jawab Klinik/BP Anisa, untuk melakukan penelitian. Pada pelaksanaannya untuk mendapatkan sampel dari populasi yang ada, peneliti melakukan skrining dengan pengkajian agar sesuai dengan kriteria inklusi dan eksklusi yang ditentukan.

Manajemen intervensi body wipe dilakukan pada malam hari saat terjadinya hot flush. Saat terjadi hot flush, sebelum diberi manajemen intervensi body wipe dilakukan pengukuran suhu inti tubuh pada responden. Pengukuran suhu inti tubuh sebelum diberi manajemen intervensi body wipe, dengan menggunakan thermometer infrared yang dilakukan oleh peneliti. Setelah pengukuran suhu inti tubuh, dilakukan intervensi body wipe dengan menempelkan body wipe pada bagian yang mengalami hot flush selama 3- 5 menit. Setelah 5 menit, body wipe diangkat. Kemudian, suhu inti tubuh pada responden, diukur kembali dengan menggunakan thermometer.

Data yang didapat dari hasil pengukuran suhu inti tubuh sebelum dan sesudah diberi manajemen intervensi body wipe dicatat dan diperiksa kembali kelengkapannya untuk dilakukan analisa. Analisis data dilakukan dengan program komputer menggunakan uji Wilcoxon yang terlebih dahulu dilakukan uji normalitas Shapiro-Wilk.

\section{HASIL PENELITIAN}

\section{Suhu inti tubuh sebelum diberi manajemen intervensi body wipe.}

Berdasarkan hasil penghitungan peneliti, peneliti menemukan karakter suhu inti tubuh sebelum diberi manajemen intervensi body wipe dan dapat di lihat pada tabel 1 . 
Jurnal Kebidanan : Jurnal Medical Science Ilmu Kesehatan Akademi Kebidanan Budi Mulia Palembang Volume.11 No.1, Juni 2021

Available online http://journal.budimulia.ac.id/

Tabel 1 Distribusi Frekuensi Wanita Fase Menopause Berdasarkan Suhu Inti Tubuh Sebelum diberi Manajemen Intervensi Body Wipe di Klinik/BP Anisa

\begin{tabular}{lccc}
\hline \multicolumn{1}{c}{ Suhu Sebelum } & Frekuensi & Persentase \\
\hline Rendah $\left(36,4^{0} \mathrm{C}-36^{0} \mathrm{C}\right)$ & 0 & $0 \%$ \\
Normal $\left(36,5^{0} \mathrm{C}-37,5^{0} \mathrm{C}\right.$ & 0 & $0 \%$ \\
Tinggi $\left(37,6^{0} \mathrm{C}-40^{\circ} \mathrm{C}\right)$ & 12 & $100 \%$ \\
\hline
\end{tabular}

Dari tabel 1 diketahui bahwa suhu inti tubuh wanita menopause sebelum diberi manajemen intervensi body wipe di Klinik/BP Anisa, sebanyak 5 wanita menopause $(41.7 \%)$ dengan suhu inti tubuh $37,6^{\circ} \mathrm{C}$, sebanyak 5 wanita menopause $(41.7 \%)$ dengan suhu inti tubuh $37,7^{\circ} \mathrm{C}$, sebanyak 2 wanita menopause (16.7\%) dengan suhu inti tubuh $37,8^{0} \mathrm{C}$.

\section{Suhu inti tubuh sesudah diberi manajemen intervensi body wipe}

Berdasarkan hasil penghitungan peneliti, peneliti menemukan karakter suhu inti tubuh sesudah diberi manajemen intervensi body wipe dan dapat di lihat pada tabel 2.

Tabel 2 Distribusi Frekuensi Wanita Fase Menopause Berdasarkan Suhu Inti Tubuh Sesudah diberi Manajemen Intervensi
Body Wipe di Klinik/BP Anisa Suhu inti tubuh sesudah diberi manajemen intervensi body wipe. Berdasarkan hasil penghitungan peneliti, peneliti menemukan karakter suhu inti tubuh sesudah diberi manajemen intervensi body wipe dan dapat di lihat pada tabel 2.

Tabel 2 Distribusi Frekuensi Wanita Fase Menopause Berdasarkan Suhu Inti Tubuh Sesudah diberi Manajemen Intervensi Body Wipe di Klinik/BP Anisa

\begin{tabular}{lccc}
\hline \multicolumn{1}{c}{ Suhu Sesudah } & Frekuensi & Persentase \\
\hline Rendah & $\left(36,4^{0} \mathrm{C}-36^{0} \mathrm{C}\right)$ & 0 & $0 \%$ \\
Normal $\left(36,5^{\circ} \mathrm{C}-37,5^{0} \mathrm{C}\right.$ & 11 & $91,7 \%$ \\
Tinggi $\left(37,6^{0} \mathrm{C}-40^{\circ} \mathrm{C}\right)$ & 1 & $8,3 \%$ \\
\hline
\end{tabular}

Dari tabel 2 diketahui bahwa suhu inti tubuh wanita menopause sesudah diberi manajemen intervensi body wipe di Klinik/BP Anisa, sebanyak 5 wanita menopause $(41,7 \%)$ dengan suhu inti tubuh $37.3^{\circ} \mathrm{C}$, sebanyak 3 wanita menopause $(25,0 \%)$ dengan suhu inti tubuh $37.4^{\circ} \mathrm{C}$, sebanyak 3 wanita menopause $(25,0 \%)$ dengan suhu inti tubuh $37,5^{\circ} \mathrm{C}$, dan 1 wanita menopause $(8,3 \%)$ dengan suhu inti tubuh $37,6^{0} \mathrm{C}$.

\section{Karakteristik Umur Wanita Menopause}

Berdasarkan hasil penghitungan peneliti, peneliti menemukan karakter umur wanita menopause dan dapat di lihat pada tabel 3.

Tabel 3 Distribusi Frekuensi Wanita Fase Menopause Berdasarkan Tingkat Umur Wanita Menopause di Klinik/BP Anisa

\begin{tabular}{lcc}
\hline \multicolumn{1}{c}{ Umur } & Frekuensi & Persentase \\
\hline Pre Menopause & 0 & $0 \%$ \\
Fase Menopause & 12 & $100 \%$ \\
Pasca Menopause & 0 & $0 \%$ \\
\hline
\end{tabular}


Jurnal Kebidanan : Jurnal Medical Science Ilmu Kesehatan Akademi Kebidanan Budi Mulia Palembang Volume.11 No.1, Juni 2021

Available online http://journal.budimulia.ac.id/

Dari tabel 3 di atas diketahui bahwa dari 12 wanita menopause yang berumur pada pre menopause tidak ada $(0 \%)$, fase menopause sebanyak 12 orang $(100 \%)$, pasca menopause tidak ada $(0 \%)$.

\section{Karakteristik Pendidikan Wanita Menopause}

Berdasarkan hasil penghitungan peneliti, peneliti menemukan karakter pendidikan wanita menopause dan dapat di lihat pada tabel 4.

Tabel 4 Distribusi Frekuensi Wanita Fase Menopause Berdasarkan Tingkat Pendidikan Wanita Menopause di Klinik/BP Anisa

\begin{tabular}{lcc}
\hline \multicolumn{1}{c}{ Pendidikan } & Frekuensi & Persentase \\
\hline Bawah (SD) & 12 & $100 \%$ \\
Menengah (SMP,SMA) & 0 & $0 \%$ \\
Atas (D3, S1, Doctor) & 0 & $0 \%$ \\
\hline
\end{tabular}

Dari tabel 4 di atas diketahui bahwa dari 12 wanita menopause yang berpendidikan bawah sebanyak 12 orang $(100 \%)$, menengah tidak ada $(0 \%)$, atas tidak ada $(0 \%)$.

\section{Karakteristik Pekerjaan Wanita Menopause}

Berdasarkan hasil penghitungan peneliti, peneliti menemukan karakter pekerjaan wanita menopause dan dapat di lihat pada tabel 5.

Tabel 5 Distribusi Frekuensi Wanita Fase Menopause Berdasarkan Tingkat Pekerjaan Wanita Menopause di Klinik/BP Anisa

\begin{tabular}{lcc}
\hline \multicolumn{1}{c}{ Pekerjaan } & Frekuensi & Persentase \\
\hline Mandiri & 12 & $100 \%$ \\
Bantuan Orang Lain & 0 & $0 \%$ \\
Bantuan Alat & 0 & $0 \%$ \\
Tergantung Secara Total & 0 & $0 \%$ \\
\hline
\end{tabular}

Dari tabel 5 diketahui bahwa dari 12 wanita menopause yang bekerja secara mandiri sebanyak 12 orang $(100 \%)$, perlu bantuan orang lain tidak ada $(0 \%)$, perlu bantuan alat $(0 \%)$, tergantung secara total tidak ada $(0 \%)$.

\section{Pengaruh manajemen intervensi hot flush dengan menggunakan body wipe.}

Analisis ini dilakukan dengan menggunakan desain pre - post test design. Uji statistik yang akan dipakai adalah uji statistik Wilcoxon. Uji Statistik Wilcoxon dipakai karena syarat uji $\mathrm{T}$ Berpasangan tidak terpenuhi. Hasil analisis dapat dilihat pada tabel 6.

Tabel 6 Pengaruh Manajemen Intervensi Hot Flush dengan menggunakan Body Wipe pada Wanita Menopause di Klinik/BP Anisa

\begin{tabular}{lccccc}
\hline \multicolumn{7}{c}{ Suhu Sebelum dan Sesudah } \\
\hline & N & Mean Rank & Sum of Ranks & Z & Sig (2-Failed) \\
\hline Negatif Ranks & 12, & 6,50 & 78,00 & $-3,274$ &, 001 \\
Positive Ranks & 0, &, 00 &, 00 & & \\
Ties & $0 \mathrm{c}$ & & & & \\
\hline Total & 12 & & & \\
\hline
\end{tabular}


Dari tabel 6, menunjukan bahwa perbedaan suhu inti tubuh sebelum dan sesudah diberi manajemen intervensi body wipe. Terdapat 12 wanita menopause dengan hasil suhu inti tubuh lebih rendah setelah diberi manajemen intervensi body wipe daripada sebelum diberi manajemen

\section{PEMBAHASAN}

Dari hasil penelitian diketahui bahwa suhu inti tubuh wanita menopause sebelum diberi manajemen intervensi body wipe di Klinik/BP Anisa, sebanyak 5 wanita menopause $(41.7 \%)$ dengan suhu inti tubuh $37,6^{\circ} \mathrm{C}$, sebanyak 5 wanita menopause $(41.7 \%)$ dengan suhu inti tubuh $37,7^{\circ} \mathrm{C}$, sebanyak 2 wanita menopause (16.7\%) dengan suhu inti tubuh $37,8^{\circ} \mathrm{C}$.

- Dari hasil penelitian pelaksanaan bahwa suhu inti tubuh wanita menopause sesudah diberi manajemen intervensi body wipe di Klinik/BP Anisa, sebanyak 5 wanita menopause $(41,7 \%)$ dengan suhu inti tubuh $37.3^{\circ} \mathrm{C}$, sebanyak 3 wanita menopause $(25,0 \%)$ dengan suhu inti tubuh $37.4^{\circ} \mathrm{C}$, sebanyak 3 wanita menopause $(25,0 \%)$ dengan suhu inti tubuh $37,5^{\circ} \mathrm{C}$, dan 1 wanita menopause $(8,3 \%)$ dengan suhu inti tubuh $37,6^{\circ} \mathrm{C}$. Menurut asumsi penulis dari hasil penelitian standar cara yang bisa membantu mengurangi intensitas rasa panas saat hot flashes datang menyerang cara sederhana dapat Anda lakukan untuk mengatasi hot flashes yaitu dengan menggunakan kompres es. Letakkan kompres es tersebut di kepala Anda pada malam hari, hal ini mungkin bisa membantu. Atau, usap wajah Anda dengan air dingin, mandi air hangat juga bisa membantu. Tetapi ada cara yang lebih simpel yang praktis dan teruji secara dermatologis yaitu dengan menggunakan body page (Tisu Basah ) yang bisa dibeli di supermarket atau apotik. berdasarkan penelitian yang dilakukan di klinik dan sebelumnya responden sudah di latih terlebih dahulu cara penggunaannya.

Berdasarkan hasil Karakteristik Umur Wanita Menopause, Karakteristik Pendidikan Wanita Menopause, Karakteristik Pekerjaan Wanita Menopause, faktor-faktor yang intervensi body wipe. Hasil statistik wilcoxon, diperoleh nilai significancy $0,001(\mathrm{p}<0,05)$, dengan demikian disimpulkan "manajemen intervensi dengan menggunakan body wipe dapat berpengaruh dalam mengatasi hot flush."

mempegaruhi pengetahuan didapatkan wanita yang memiliki pengetahuan kurang yaitu pendidikan terakhir SD sebanyak 12 responden $(100 \%)$. Tingkat pendidikan sangat mempengaruhi pengetahuan seseorang, karena semakin tinggi tingkat pendidikan seseorang maka semakin cepat menerima dan mengerti apa yang dianjurkan oleh peneliti. Masa menopause ini mulai terjadi pada ratarata umur 50 tahun, tetapi bisa juga terjadi secara normal pada wanita yang berusia diatas atau dibawah usia 50 tahun (Mulyani, 2013), Dilihat dari umur didapatkan 12 responden (100 \%) umur responden berada difase menopause. Wanita pada masa menopause akan mengalami penurunan hormon estrogen dan hormon progesteron. Hal ini dapat menimbulkan beberapa gejala yang umum terjadi yaitu hot flashes (rasa panas dari wajah hingga dada), night sweat (berkeringat di malam hari), dryness vaginal (kekeringan vagina), penurunan daya ingat, insomnia, depresi, fatique (mudah capek), penurunan libido, drypareunia (rasa sakit ketika berhubungan seksual), dan incontinence urinary (beser). Gejala-gejala menopause tersebut dialami oleh banyak wanita hampir di seluruh dunia, sekitar 70-80\% wanita Eropa, $60 \%$ di Amerika, 57\% di Malaysia, 18\% di China $10 \%$ di Jepang dan $10 \%$ Indonesia (Proverawati, 2010). Dari penelitian yang dilakukan oleh peneliti didapatkan wanita menopause bisa bekerja mandiri tanpa bantuan orang lain dalam melakukan aktifitas sehari - hari, 12 responden (100\%), wanita bisa bekerja mandiri mempunyai kesempatan untuk mendapatkan informasi lebih banyak, sedangkan wanita yang tidak bisa mandiri atau harus dibantu orang lain dalam beraktifitas terbatas sekali dalam 
mendapatkan informasi. Hot flashes muncul secara tiba-tiba, sering terjadi pada siang hari dan malam hari, dan berbeda durasi dan frekuensi antara wanita satu dengan yang lainnya (Andrews, 2010). Beberapa wanita mengalami hot flashes setiap jam atau setiap hari, sedangkan untuk yang lain hanya dapat terjadi sesekali. Mayoritas wanita mengalami hot flashes selama satu atau dua tahun, tetapi $15 \%$ memilikinya tanpa henti selama 10, 20,

\section{KESIMPULAN}

Dari hasil penelitian ini, maka dapat di simpulkan sebagai bahwa terdapat perbedaan gambaran hot flush sebelum dan sesudah diberikan manajemen intervensi dengan menggunakan body wipe pada ibu menopause di Klinik/BP dengan $\mathrm{p}$ value $=0.01$.

\section{SARAN}

\section{Bagi Klinik/BP Anisa}

Agar dapat menyediakan body wipe atau intervensi lainnya, untuk mengurangi hot flush pada wanita menopause. Sehingga wanita menopause tidak mengalami kepanasan atau gangguan tidur saat malam hari dan juga wanita menopause tidak salah melakukan manajemen untuk mengatasi hot flush dengan cara lain yang dapat menimbulkan masalah baru. Body Wipe yang digunakan juga harganya ekonomis dan mudah didapat.

2. Bagi Intitusi Akbid Budi Mulia Palembang Menjadi informasi bagi pengajar maupun mahasiswa untuk mengembangkan ilmu dan ketrampilan khususnya dibidang keperawatan maternitas tentang ibu menopause yang mengalami hot flush.

3. Bagi Peneliti Lain

Perlu penelitian lebih lanjut dengan jumlah sampel > 50 dan faktor-faktor lain yang dapat dijadikan manajemen intervensi untuk mengatasi hot flush.

4. Bagi Ibu Menopause

Dapat menambah pengetahuan dan wawasan ibu menopause mengenai manajemen intervensi hot flush dengan body wipe, sehingga dapat mengatasi hot flush dengan menggunakan body wipe. atau 30 tahun (Kronenberg, 2010). Dampak hot flashes cukup besar dan sering diremehkan. Hot flashes dapat mengganggu pekerjaan dan kegiatan sehari-hari serta tidur, menyebabkan kelelahan, hilangnya konsentrasi dan gejala depresi, yang semuanya bisa mengganggu kehidupan keluarga serta fungsi seksual dan hubungan pasangan (Sikon \& Thacker, 2004).

\section{DAFTAR PUSTAKA}

Andira .D, 2010. Seluk-beluk menopause. Garai ilmu, Yogyakarta.

Andrews, G, (2010), Buku Ajar Kesehatan Reproduksi Wanita: EGC. Jakarta.

Kemenkes RI. 2013. Gambaran Kesehatan Lanjut Usia di Indonesia.Buletin Jendela Data $66 \quad 62$ dan Informasi Kesehatan : Jakarta.

Kapita selekta kuesioner pengetahuan dan sikap dalam penelitian kesehatan. Jakarta: Salemba Medika Davis, S. R., et al. (April, 2015).

Klinik/BP Anisa, (2020). Profil Data Klinik/BP Anisa. Mainan, Sembawa, Banyuasin.

Lapau Buchari, dr. MPH, 2012. Metodologi Kesehatan Kesehatan. Iksaka Banu: Jakarta.

Notoatmodjo Soekidjo. 2010. Metodologi Penelitian Kesehatan. Rineka Cipta: Jakarta.

Noerpramana, Noor Pramono.2006. Fitoserm:Terapi Terkini dalam Mengatasi Masalah Kesehatan Menopause: Jakarta.

Proverawati, A \& Sulityawati, E. 2010. Menopause dan Sindrom Premenopause. Yogyakarta: Nuha Medika.

Profil kesehatan Indonesia tahun 2016. Jakarta.

Sugiyono. 2010. Metode Penelitian Kuantitatif Kualitatif dan R \& D.Alfa Beta: Bandung. 
Jurnal Kebidanan : Jurnal Medical Science Ilmu Kesehatan Akademi Kebidanan Budi Mulia Palembang Volume.11 No.1, Juni 2021

Available online http://journal.budimulia.ac.id/ 
